\title{
Hongos Útiles Y tóXICOS SEgún LOS YUYEROS DE LA PAZ Y LoMA Bola (Valle de Traslasierra, Córdoba, Argentina)
}

\author{
MARCO FLAMINI'1 MARÍA EUGENIA SUÁREZZ2,3 y GERARDO ROBLEDO ${ }^{4,5}$
}

\begin{abstract}
Summary: Useful and toxic fungi according to the "yuyeros" of La Paz and Loma Bola (Valle de Traslasierra, Córdoba, Argentina). The importance of macrofungi -in both, practical and symbolic termsamong the different cultures can be appreciated in elements of their traditional art, mythology or material culture, and in the diversity of uses that they have; besides, they constitute an important source of monetary income and food for many families all over the world. In Argentina, and particularly in the province of Córdoba, published ethnomycological data are scarce and fragmentary. In order to contribute to reverse this situation, a qualitative ethnomycological research was carried out among Criollo peasants of the towns of La Paz and Loma Bola (Córdoba). Data were obtained through open interviews, the "walks-throughthe-environment" technique, gathering of fungi and participant observation. Thirty one species were studied; 12 of them are used for one or more purposes, and 10 have some level of toxicity, according to the interviewees. A detailed description and analysis of the knowledge and uses of medicinal, ornamental, veterinary, dyeing and food species is presented. Vernacular knowledge allows people to discern among toxic and food species. The analysis of the results suggests that fungi are relevant for local peasants, and highlight the necessity and importance of the recovery and conservation of native forests of Córdoba.
\end{abstract}

Key words: Ethnobiology, mycology, ethnomycology, traditional knowledge, lichens, mushrooms, macrofungi.

Resumen: La relevancia práctica y simbólica que poseen los macrohongos en las distintas culturas se aprecia en elementos del arte tradicional, la mitología o la cultura material y en la diversidad de aplicaciones que poseen; constituyen además una importante fuente de ingresos y alimento para numerosas familias a nivel mundial. En Argentina, y particularmente en Córdoba, los datos etnomicológicos disponibles son escasos y fragmentarios. Para contribuir a revertir esta situación, se realizó una investigación etnomicológica con campesinos criollos de los poblados cordobeses de La Paz y Loma Bola. Se trabajó con un enfoque cualitativo; los datos se recopilaron mediante entrevistas abiertas, recorridos por el entorno con recolección de material de referencia y observación participante. Se estudiaron 32 especies fúngicas, de las cuales 12 poseen algún uso práctico y 11 algún grado de toxicidad, según los entrevistados. Se describen y analizan pormenores de conocimientos y usos de especies medicinales, ornamentales, tintóreas, alimenticias y veterinarias. Los saberes vernáculos permiten a la gente discernir entre especies tóxicas y alimenticias con certeza. El análisis de los resultados indica que los hongos son relevantes para los campesinos y resaltan la necesidad e importancia de la conservación y recuperación del bosque chaqueño serrano cordobés.

Palabras clave: Etnobiología, micología, etnomicología, conocimiento tradicional, líquenes, setas, macrohongos.

1 Cátedra de Antropología, Facultad de Ciencias Exactas, Físicas y Naturales, Universidad Nacional de Córdoba, Córdoba, Argentina.flaminim@gmail.com

2 Universidad de Buenos Aires, Facultad de Ciencias Exactas y Naturales, Departamento de Biodiversidad y Biología Experimental, Grupo de Etnobiología. Buenos Aires, Argentina.

3 CONICET-Universidad de Buenos Aires, Instituto de Micología y Botánica- CONICET (INMIBO). Buenos Aires, Argentina. eugesuarez78@gmail.com

${ }^{4}$ Laboratorio de Micología,Instituto Multidisciplinario de Biología Vegetal - CONICET, Universidad Nacional de Córdoba, Córdoba, Argentina

${ }^{5}$ Fundación FungiCosmos, Córdoba, Argentina. 


\section{INTRODUCCIÓN}

La etnomicología es la rama de la etnobiología dedicada a investigar el papel de los hongos en las diversas culturas; en otras palabras, es un campo interdisciplinar que estudia las relaciones recíprocas entre uno o más grupos humanos y los hongos mediante la descripción, interpretación y análisis de los usos, creencias, percepciones, conocimientos y prácticas, tanto actuales como antiguos (Arora \& Shepard, 2008; Yamin-Pasternak, 2011). Desde su establecimiento formal a mediados del siglo pasado, es indiscutible el fuerte y rápido desarrollo que vivió la materia hasta la actualidad, aunque la mayoría de los trabajos provienen del estudio en comunidades y pueblos mexicanos (Moreno Fuentes et al., 2001; Ruán Soto, 2007).

Son ya numerosos los estudios que han demostrado la amplitud del conocimiento micológico tradicional y el destacado rol de los hongos, en especial los macrohongos (i.e. hongos con estructuras macroscópicas), en la vida cotidiana de muchas comunidades humanas alrededor del mundo: su relevancia práctica y simbólica se puede apreciar en el arte tradicional, en la mitología, en la cultura material y en la utilización para fines medicinales, alimenticios, enteogénicos, veterinarios, tintóreos, entre otros (Boa, 2004; Arora \& Shepard, 2008; Malaisse, 2010; Yamin-Pasternak, 2011). Por ello, los hongos macroscópicos conforman uno de los grupos más importantes entre los productos forestales no madereros (PFNM) a nivel mundial, y constituyen real o potencialmente una significativa fuente de ingresos económicos y de alimento para numerosas familias que los recolectan (Boa, 2004; Kalac, 2009; Malaisse, 2010).

En Argentina, a excepción de unos pocos trabajos (Keller, 2008; Flamini et al., 2015), la mayor cantidad de información etnomicológica se encuentra dispersa en investigaciones etnobotánicas realizadas desde distintos enfoques y en diferentes regiones del país, pero cuyo interés está centrado en las interrelaciones entre plantas y humanos y no en las existentes entre hongos y humanos (Filipov, 1997; Arenas, 2003; Domínguez Díaz, 2010; Hernández et al., 2010; Keller, 2010; Martínez, 2007, 2010; Martínez \& Cúneo, 2009; Ochoa et al., 2010; Scarpa, 2012, 2013; Suárez \& Arenas, 2012; Scarpa \& Rosso, 2014; Suárez, 2014). También se pueden encontrar datos de interés para la etnomicología en trabajos abordados desde la micología, la biología o la ecología (p. ej. Deschamps, 2002; Acosta, 2009; Niveiro et al., 2009; Robledo \& Urcelay, 2009; Fernández et al., 2012). Con todo, salvo contadas obras (Keller, 2008; Flamini et al., 2015; Suárez, 2014), la mayoría de los estudios citados se limitan a la mención y/o descripción de usos prácticos y algunos nombres vernáculos, dejando de lado el examen pormenorizado de las percepciones, clasificaciones y creencias locales, entre otros. Lo antedicho es particularmente válido para la provincia de Córdoba, ya que aparte de la información que brinda el trabajo etnomicológico de Flamini et al. (2015), sólo se cuenta con información parcial y general sobre usos y hongos útiles de contadas especies: Calvatia cyathiformis (Bosc) Morgan, Phlebopus bruchii (Speg.) Heinem. \& Rammeloo, Suillus granulatus (L.) Roussel, Suillus luteus (L.) Roussel, Usnea spp. (Deschamps, 2002; Martínez \& Planchuelo, 2003; Martínez, 2010; Arias Toledo, 2006; Trillo \& Demaio, 2007; Furlan et al., 2011). De este modo, la etnomicología en Córdoba y en el país resulta ser un campo prácticamente inexplorado.

El presente trabajo es la prosecución y complemento de uno anterior (Flamini et al., 2015), y pretende contribuir al conocimiento de la etnomicología de la provincia, específicamente al de los habitantes de La Paz y Loma Bola. Para ello se plantearon como objetivos: a) Compendiar y describir en detalle los diferentes usos que asignan los yuyeros a los hongos y líquenes de su entorno e identificar las especies correspondientes; b) Analizar, desde una perspectiva etnomicológica, el empleo de cada hongo estudiado en función del contexto sociocultural de las personas involucradas, contrastando los datos con los resultados hallados por otros autores entre otros grupos humanos de la región.

\section{Materiales y Métodos}

\section{Contexto ambiental y cultural}

La investigación se desarrolló en el valle de Traslasierra de la Provincia de Córdoba, Argentina, en los poblados de $\mathrm{La} \mathrm{Paz}\left(31^{\circ} 56^{\prime} 00^{\prime \prime} \mathrm{S} 65^{\circ} 12^{\prime} 00^{\prime \prime} \mathrm{O}\right)$ y Loma Bola $\left(32^{\circ} 13^{\prime} 08^{\prime \prime} \mathrm{S} 65^{\circ} 01^{\prime} 34^{\prime \prime O}\right)$ (Fig. 1), ubicados en el Departamento San Javier. La localidad 


\section{Flamini et al. - Hongos útiles y tóxicos según los yuyeros de La Paz y Loma Bola}

de La Paz está situada a 750 m.s.n.m. y cuenta con una población total de 1189 habitantes (INDEC, 2010). Loma Bola es un poblado que depende del municipio de La Paz, se encuentra a tan sólo $3 \mathrm{~km}$ de la plaza central de La Pazy cuenta con 418 habitantes (INDEC, 2010). Las principales actividades económicas de la zona son la producción de olivares y de plantas aromáticas; además hay una gran afluencia turística, principalmente durante el verano, por lo que muchas familias se dedican a la producción de artesanías y productos regionales para la venta al público (Buguña \& Cometta, 2010). Desde el punto de vista fitogeográfico, el área de estudio se encuentra en el Distrito Chaqueño Serrano de la provincia Chaqueña, que se caracteriza por una vegetación dominada por bosques xerófilos de 'orco quebracho' [Schinopsis lorentzii (Griseb.) Engl., Anacardiaceae], 'molle' [Lithraea molleoides (Vell.) Engl., Anacardiaceae] y 'coco' (Zanthoxylum coco Gillies ex Hook. f. \& Arn., Rutaceae) (Cabrera, 1971; Luti et al., 1979). Sin embargo, desde hace varias décadas los bosques de las zonas serranas de la provincia de Córdoba vienen sufriendo grandes transformaciones en su estructura, fisonomía y distribución, causadas principalmente por el avance de las urbanizaciones, la agricultura, la deforestación, los incendios, la invasión de especies exóticas y el sobrepastoreo (Aragón \& Morales, 2003; Zak et al., 2004). Por esos motivos, el paisaje actual está representado por un mosaico de manchones de bosque de especies nativas o de especies nativas y exóticas, junto con fachinales y pastizales de sustitución (Zak et al., 2004). Además, en la zona existen extensas áreas forestadas con Pinus spp. (Pinaceae) que forman manchones de bosque monoespecíficos.

El contexto cultural de la zona de estudio está conformado por habitantes con distintos orígenes e historias de vida. En particular, la información disponible sobre aspectos socioculturales de las poblaciones de campesinos serranos de Traslasierra es realmente escasa, por lo cual se conformó un diagnóstico rural rápido de exploración (Coirini \& Robledo, 1999) mediante la complementación de datos bibliográficos con otros obtenidos a campo. A partir del mismo se puede afirmar desde una perspectiva ética (Arenas \& Martínez, 2012), que los colaboradores con quienes se trabajó son criollos (gente local no-indígena, en general de ascendencia mestiza) que viven o han pasado al menos parte de su vida en hogares dispersos en las laderas de las serranías, alejados del centro del pueblo e inmersos en

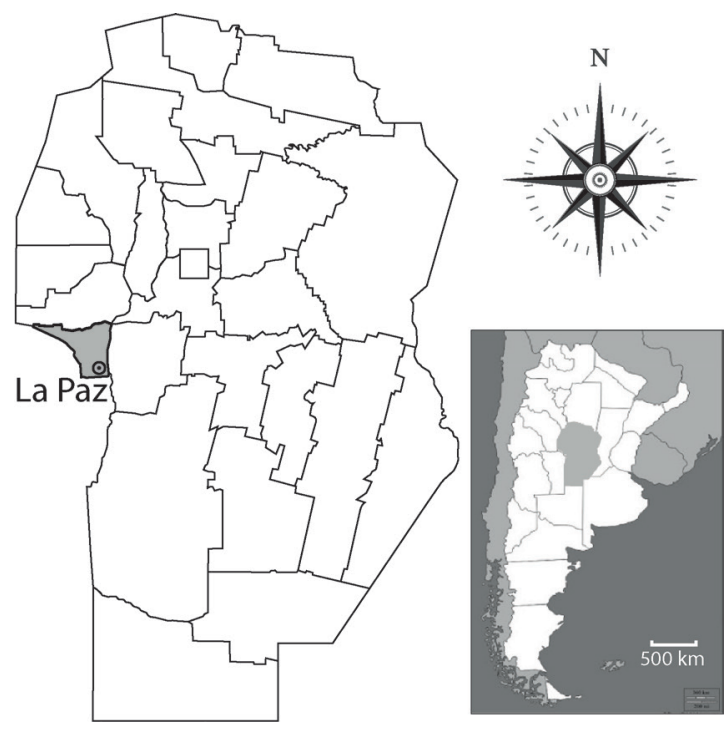

Fig. 1. Mapa del área de estudio, en la provincia de Córdoba, Argentina.

el monte. Todos hablan español como lengua materna. Actualmente, muchos viven en casas construidas a partir de barro, paja, rocas y troncos de árboles de la zona, con techo de paja y cañas, sin tendido eléctrico, gas natural ni agua corriente; otros están asentados en casas de material en los poblados de Loma Bola y La Paz. Habitualmente la vivienda está habitada por la familia extensa. Por las particularidades de su vida cotidiana, este grupo de personas mantiene un contacto íntimo con su entorno natural y cuenta con una larga tradición en la recolección, uso y comercialización de hierbas y hongos silvestres, motivo por el cual se autodenominan "yuyeros" (Fig. 2A). La economía familiar depende de actividades laborales informales, discontinuas y de marcada fluctuación estacional: venta de bienes y servicios vinculados al turismo (comercialización de hierbas aromáticas, hongos silvestres y productos regionales, guías de cabalgatas, etc.), changas y trabajos ocasionales como albañiles, trabajos en quintas y estancias con animales y cultivos, venta de leña, entre otros. Vale la pena destacar que el comercio de hierbas silvestres alcanza a involucrar hasta un $80 \%$ de los habitantes de la zona y es en gran medida la base de su subsistencia (Lagrotteria \& Affolter, 1999). Particularmente las mujeres, además de realizar las tareas de mantenimiento del hogar, suelen trabajar como empleadas domésticas o cumplir distintas labores en hoteles y alojamientos 


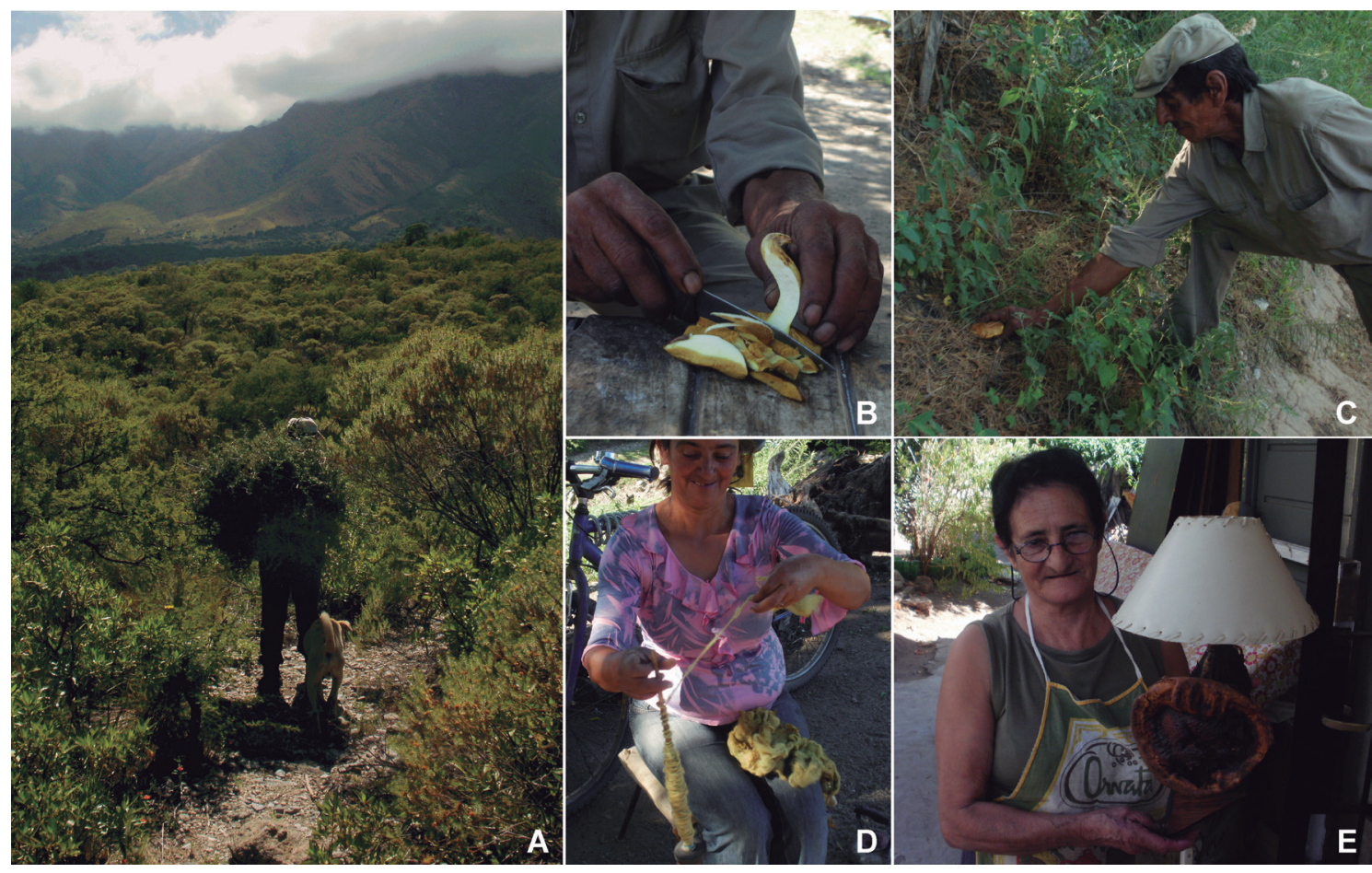

Fig. 2. Los yuyeros y sus hongos. A: Marcos cargando yuyos junto a su perro acompañante. B: Roberto picando "hongos de pino" (Suillus granulatus). C: Genaro recolectando "hongos de pino" (S. granulatus). D: Guillermina hilando lana de oveja teñida con "barba de piedra" (Usnea spp.). E: Maruca sosteniendo su hongo-velador donde se aprecia el píleo de Ganoderma resinaceum. Fotos: M. Flamini.

de la zona, y muchas veces desarrollan actividades vinculadas al arte textil (ya sea para venta o uso en el seno familiar) tales como hilados de lana de oveja, tinciones con anilinas, hongos y vegetales, y la confección de diversos tejidos. Los terrenos y casas donde vivieron sus antepasados hoy son en su mayoría propiedad de otras personas y se encuentran alambrados. En muchos casos las familias fueron coaccionadas para vender sus propiedades, y en otros fueron directamente despojadas de las tierras en las que históricamente habitaron; tan sólo tres son propietarios. El alcoholismo (especialmente entre los varones) y el Mal de Chagas son las principales problemáticas sanitarias que sufren.

\section{Recopilación y análisis de los datos y materiales}

La investigación se enmarca teórica y metodológicamente en la etnomicología, particularmente en su vertiente cualitativa (Mello Amorozo \& Viertler, 2008; Arenas \& Martínez,
2012). Se trabajó mediante la metodología ya clásica en etnobiología, que involucra tanto trabajo de campo como trabajo de gabinete y laboratorio (Martin, 1995; Yamin-Pasternak, 2011; Arenas \& Martínez, 2012).

Se realizaron tres viajes de aproximadamente un mes de duración cada uno entre febrero de 2012 y marzo de 2013. Los trabajos de campo se concentraron en los meses de verano y principios del otoño, que son épocas de lluvia en la zona y por ende en las que resulta más probable encontrar estructuras fúngicas macroscópicas. Durante las campañas se entrevistó a un total de 14 personas (5 mujeres y 9 varones) de 46 a 99 años de edad, con quienes se tuvo un mínimo de 3 y un máximo de 7 encuentros de entre 1 y hasta 4 horas de duración cada uno.

Antes de comenzar el trabajo, se obtuvo el consentimiento informado de manera oral de cada una de las personas consultadas, siguiendo las recomendaciones del código de ética de la Sociedad Internacional de Etnobiología (ISE, 2006). Para la 


\section{Flamini et al. - Hongos útiles y tóxicos según los yuyeros de La Paz y Loma Bola}

selección de las personas entrevistadas se utilizó el método "bola de nieve" y se privilegió el trabajo con personas calificadas o informantes clave (Martin, 1995; Bernard, 2000).

Los datos se recopilaron a través de tres métodos: a) recorridos a pie por la zona en compañía de los entrevistados, b) entrevistas abiertas y semiestructuradas, con el apoyo de una guía temática confeccionada con antelación, y c) observación participante (Martin, 1995; Bernard, 2000; Guber, 2001; Arenas \& Martínez, 2012). Durante las caminatas se recolectó material biológico de referencia. Para la recolección y conservación de las muestras fúngicas se siguieron los lineamientos descriptos por Robledo \& Urcelay (2009). Se recogieron también muestras de plantas que estaban vinculadas a los hongos, ya sea porque eran sustrato, porque según los campesinos guardaban algún otro tipo de asociación biológica, o porque se las nombraba en algún proceso o actividad que involucraba hongos. Los vegetales fueron recolectados y herborizados en el campo en pliegos de papel, y posteriormente trasladados al laboratorio para su identificación. Los nombres científicos de hongos y vegetales estudiados siguen las propuestas del "Index Fungorum" (http:// www.indexfungorum.org) y de "The Plant List" (2013) respectivamente. Una vez identificados, los materiales se depositaron en el Herbario del Museo Botánico (CORD) de la Universidad Nacional de Córdoba.

La metodología de análisis de datos consistió en un estudio pormenorizado y de interpretación conjunta y holística del contenido de las entrevistas realizadas, de los datos provenientes de la observación participante y de la información encontrada en la bibliografía consultada, en función de los objetivos planteados (González Monteagudo, 2000; Guber, 2001; Arenas \& Martínez, 2012; Wahyuni, 2012). Los análisis se realizaron considerando tanto la perspectiva del grupo humano bajo estudio (perspectiva émica) como el punto de vista de la ciencia académica (perspectiva ética) (Arenas \& Martínez, 2012).

\section{Resultados y Discusión}

A lo largo de la investigación se identificaron 32 especies de hongos conocidas por los colaboradores
(Flamini et al., 2015); de ellas, 11 pueden ser tóxicas según los entrevistados y 12 tienen algún tipo de aplicación práctica. A continuación se detallan y analizan los resultados relativos a ambos casos.

\section{Hongos tóxicos}

Solamente dos especies han sido descriptas por los yuyeros como hongos tóxicos para los humanos: Chlorophyllum molybdites (G. Mey.) Massee (Fig. 3A) y Agaricus sp. (Fig. 3B). Sin embargo, mencionan que Phlebopus bruchii y Suillus granulatus (Fig. 3C) -especies utilizadas con fines alimenticios-, tienen algún grado de toxicidad cuando están negros o amojosados (i.e. basidiomas atacados por moho) y, según algunos entrevistados, la gleba de los llamados "polvillo del diablo" (Fig. $3 \mathrm{D}, \mathrm{E})$ también puede tener efectos tóxicos al emplearla para fines medicinales (Tabla 1).

En cuanto a Agaricus sp. y Chlorophyllum molybdites, ningún entrevistado conoce a alguien que los haya consumido siquiera por error, ni tampoco saben con precisión la gravedad del problema que ocasionaría su ingestión o las formas de tratamiento; sólo apuntan que su consumo hace mal al estómago y que todos saben que no se debe comer. Afirman que el mero hecho de manipularlos no genera problemas, aunque algunos aclaran que lo mejor es lavarse las manos después de haber estado en contacto con ellos. Aseguran que el veneno no se concentra en ninguna parte del hongo en especial, sino que todo el basidioma es tóxico.

Dado el consenso generalizado entre los pobladores sobre la toxicidad de estos hongos, resulta de suma importancia para los yuyeros poder reconocerlos, lo cual realizan en base a características morfológicas discernibles a simple vista y que contrastan con aquellas que presentan los hongos alimenticios de la zona. Entre los principales caracteres se destacan:

1. La forma del basidioma y el himenóforo laminar: es como una sombrillita (basidioma), y tiene como un librito por abajo, como unas hojitas larguitas (laminillas del himenóforo).

2. El píleo y el estípite blancos, y las laminillas de color marrón oscuro o blanco: es todo blanco por arriba y el palito, pero es negro, marrón oscuro o blanco por abajo.

3. Presencia de restos de velo universal sobre el píleo: tiene unas casquitas en la parte de arriba. 
Bol. Soc. Argent. Bot. 53 (2) 2018
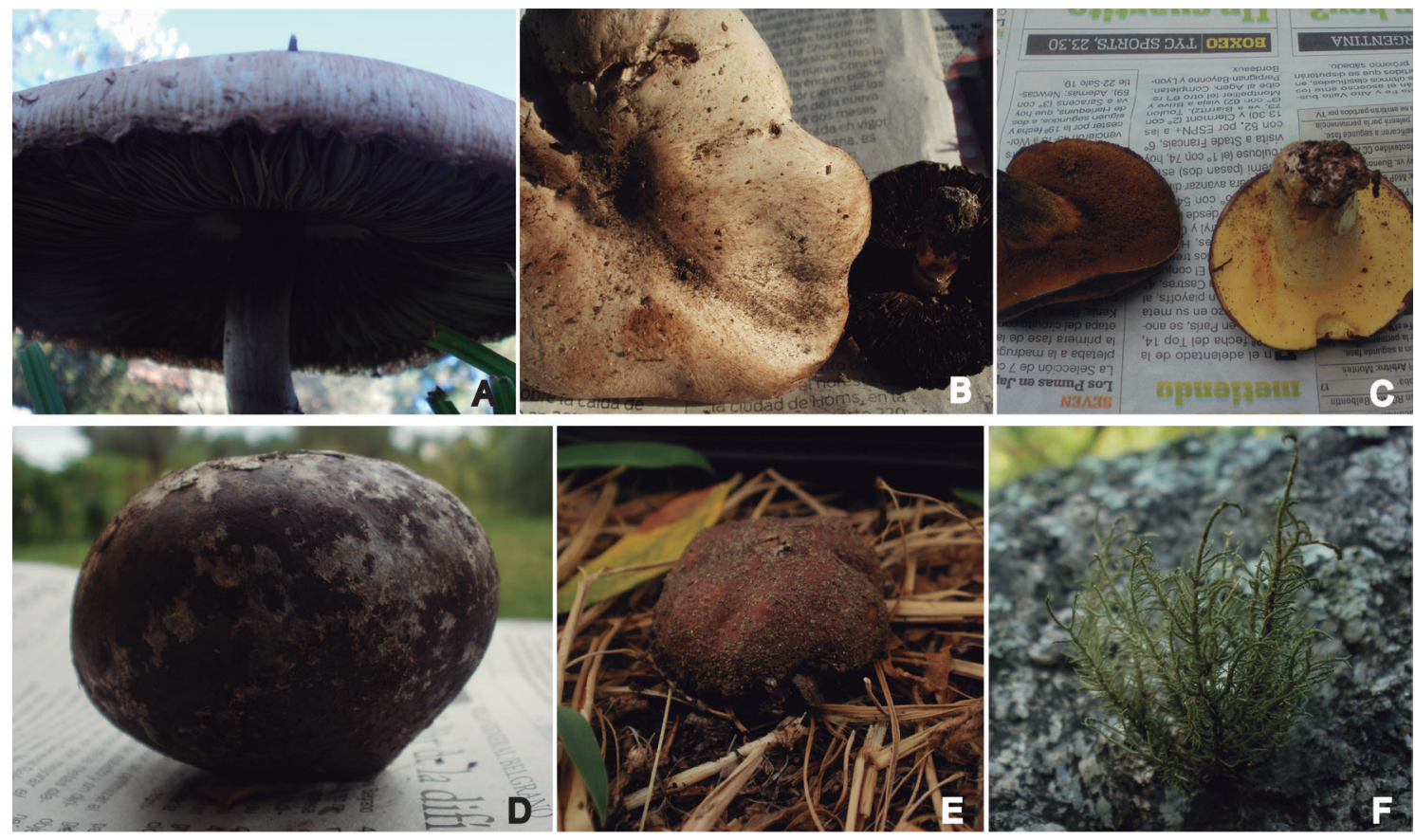

Fig. 3. Algunos hongos y líquenes recolectados durante los recorridos por el bosque. A: "Hongo Veneno", Chlorophyllum molibdites. B: "Hongo veneno", Agaricus sp. C: "Hongo de pino", Suillus granulatus. D: "Polvillo del diablo", Mycenastrum corium. E: "Polvillo del diablo", Disciseda candida. F: "Barba de piedra", Usnea spp. Fotos: M. Flamini.

Por otra parte, los yuyeros sostienen que Phlebopus bruchii y Suillus granulatus, que son hongos alimenticios, no deben ser ingeridos cuando alguna parte del basidioma está negra o aguachenta, dado que en ese estado hace mal a la panza (afecta al aparato digestivo). Algunos comentan que en ese estado no deben siquiera recolectarse; otros opinan que se pueden juntar si el área afectada es pequeña y se la puede cortar. Todos coinciden en que desconocen casos de intoxicación en la zona o las formas de tratamiento, pero algunos consideran que un curandero podría solucionarlo.

De acuerdo a Domínguez \& Hernández Caffot (2011), en la zona de estudio existen nueve especies de hongos tóxicos: Agaricus sp. (sección Xanthoderma), Amanita phalloides (Vaill. ex Fr.) Link, Amanita muscaria (L.) Lam., Chlorophyllum molybdites, Coprinopsis atramentaria (Bull.) Redhead, Vilgalys \& Moncalvo, Lepiota cristata (Bolton) P. Kumm., Leucocoprinus birnbaumii (Corda) Singer, Psilocybe coronilla (Bull.) Noordel. y Paxilus involutus (Batsch) Fr. Como puede verse, las referencias a hongos tóxicos mencionadas por los entrevistados se condicen con la información académica disponible, al menos respecto a las especies C. molybdites y Agaricus sp. Aunque el material de referencia recolectado para Agaricus sp. no permite asegurar la identidad específica del mismo, los datos registrados en el momento de colecta no indican que los basidiomas tuvieran olor fuerte y desagradable, ni el píleo o contexto coloración amarillenta al rozarse o cortarse. Si bien esto sugiere que la especie referida por los entrevistados como tóxica no pertenece a la sección Xanthoderma y quizás entonces no sea tóxica, dada la alta similitud que existe entre distintas especies del género Agaricus, se justifica igualmente la actitud cautelosa que adoptan los entrevistados al considerar a los Agaricus spp. como tóxicos o potencialmente tóxicos. De manera similar, la distinción entre Suillus granulatus (comestible) y Paxillus involutus (tóxico), se basa en diferencias mínimas ya que poseen una gran similitud morfológica, se distribuyen en las 


\section{Flamini et al. - Hongos útiles y tóxicos según los yuyeros de La Paz y Loma Bola}

mismas zonas ecológicas y ambas se asocian a coníferas. En esta línea, cobra mucho sentido que el reconocimiento de especies de hongos tóxicos se base y haga hincapié en el contraste de características propias de dichos hongos y las de los alimenticios. Asimismo, existen referencias científicas sobre los peligros de intoxicación por consumo de P. bruchii y S. granulatus cuando los basidiomas se encuentran mojados, con moho o partidos (Domínguez \& Hernández Caffot, 2011), lo cual refuerza la importancia de las medidas que adoptan los yuyeros al seleccionar basidiomas en buen estado.

La ausencia de intoxicaciones que mencionan los entrevistados podríamos atribuirla a los saberes especializados de quienes recolectan hongos y a los cuidados que ponen en la tarea, que son al parecer heredados de generaciones previas, y no conocimientos adquiridos por experiencias personales o de allegados. Ninguno de los campesinos ha sufrido intoxicaciones ni conocen casos que hayan ocurrido en la zona, lo cual es destacable, ya que no es inusual encontrar casos de intoxicación accidental en las comunidades alrededor del mundo que consumen y recolectan hongos habitualmente (Montoya et al., 1998; Barron, 1999; García, 2004; Christensen et al., 2008).

No existe consenso entre los yuyeros sobre la toxicidad de los "polvillo del diablo" (Tabla 1) para humanos $u$ otros animales. Estos hongos son empleados en medicina humana y veterinaria vernáculas como cicatrizantes, para lo cual se aplica la gleba sobre las heridas (vide infra). Según algunos campesinos el problema estaría precisamente en el contacto de la gleba con la sangre. Sin embargo, al igual que lo referido para los demás hongos considerados tóxicos, no se conoce con exactitud cuáles son las dificultades que conllevaría, ni cómo tratarlas, y tampoco se conocen casos concretos de intoxicación. Otros entrevistados creen que se puede usar la gleba sin riesgo alguno si se tiene la precaución de mezclarla con aceite de 'girasol' (Helianthus annuus L., Asteraceae) o de aplicar primero el aceite y encima la gleba, para evitar así que el polvillo se asiente en la sangre. De todas formas, la recomendación general es usar poca cantidad de gleba. En definitiva, las opiniones referidas se pueden resumir en las siguientes cuatro posturas:
1. La utilización de la gleba con fines medicinales y veterinarios no acarrea efectos adversos.

2. La gleba se puede utilizar para fines veterinarios y medicinales pero teniendo cuidado en las dosis y considerando que los humanos son más sensibles que los animales (estos últimos poseen un cuero más grueso, cualidad que les conferiría mayor resistencia a potenciales efectos nocivos).

3. La gleba sólo puede ser utilizada en animales.

4. La gleba es tóxica y no se debe usar ni en animales ni en humanos.

A pesar de la diversidad de opiniones, un análisis integral y amplio de la información reunida permite concluir que la gleba puede ser utilizada tanto en animales como en humanos, aunque probablemente deba cuidarse la dosis administrada como sucede con cualquier medicina. Esta afirmación se basa, por un lado, en que muchos entrevistados han utilizado y utilizan de manera continuada la gleba de los "polvillo del diablo" en animales y en humanos, sin que se hayan registrado casos de intoxicación (según los testimonios recogidos); y por otro lado, en que existen numerosas referencias que documentan los usos de la gleba de Gasteromycetes para los mismos fines tanto entre criollos de la provincia de Córdoba (Martínez, 2010; Martínez \& Luján, 2011) y de otras provincias (Scarpa, 2012), como entre indígenas del país (Filipov, 1997; Scarpa \& Rosso, 2014; Suárez, 2014) y del mundo (Mapes et al., 1981; Burk, 1983; Coetzee \& van Wyk, 2009). Vale la pena aclarar que en algunas investigaciones se ha llegado a proponer al género Calvatia, y en particular a $C$. cyathiformis como un importante agente causante de alergias y otras reacciones adversas debido a la inhalación de grandes cantidades de esporas (Coetzee \& van Wyk, 2009). Sin embargo, entre los problemas que causaría el uso medicinal de los "polvillo del diablo" nunca se mencionaron trastornos vinculados a la inhalación de esporas.

\section{Hongos útiles}

Los usos registrados para las 12 especies destacadas se organizaron ad hoc en cinco categorías: medicinales, veterinarios, tintóreos, alimenticios y ornamentales, que serán tratadas a continuación.

\section{Medicinales, hongos que curan}

Se registraron 9 especies con usos medicinales: Usnea amblyoclada, Usnea angulata, Bovista 
Tabla 1. Especies fúngicas útiles y tóxicas estudiadas, sus nombres vernáculos, categoría, parte utilizada y modalidad de uso. Referencias: $\mathrm{AL}=$ alimenticio, MED= medicinal, OR= ornamental, $\mathrm{Tl}=$ tintóreo, $\mathrm{TÓ}=$ tóxico, VET= veterinario.

\begin{tabular}{|c|c|c|c|c|}
\hline $\begin{array}{l}\text { FAMILIA/Nombre Científicol } \\
\text { Voucher (col. M. Flamini) }\end{array}$ & Nombre Vernáculo & Categoría & $\begin{array}{l}\text { Parte } \\
\text { Utilizada }\end{array}$ & Modo de Uso \\
\hline \multicolumn{5}{|l|}{ AGARICACEAE } \\
\hline Agaricus sp.; 23 & Hongo veneno & TÓ & & \\
\hline Bovista cunninghamii Kreisel; 52 & Polvillo del diablo & MED, VET & Gleba & Cicatrizante \\
\hline Calvatia cyathiformis (Bosc) Morgan; 54 & Polvillo del diablo & MED, VET & Gleba & Cicatrizante \\
\hline Calvatia fragilis (Quél.) Morgan; 53 & Polvillo del diablo & MED, VET & Gleba & Cicatrizante \\
\hline $\begin{array}{l}\text { Chlorophyllum molybdites (G. } \\
\text { Mey.) Massee ex P. Syd.; } 49\end{array}$ & Hongo veneno & TÓ & & \\
\hline Disciseda candida (Schwein.) Lloyd; 1 & Polvillo del diablo & MED, VET & Gleba & Cicatrizante \\
\hline Mycenastrum corium (Guers.) Desv.; 2, 58 & Polvillo del diablo & MED, VET & Gleba & Cicatrizante \\
\hline \multicolumn{5}{|c|}{ BOLETINELLACEAE } \\
\hline $\begin{array}{l}\text { Phlebopus bruchii (Speg.) } \\
\text { Heinem. \& Rammeloo; 55, } 57\end{array}$ & Hongo de coco & $\mathrm{AL}$ & Talo entero & Alimentación, venta \\
\hline \multicolumn{5}{|l|}{ GANODERMATACEAE } \\
\hline Ganoderma resinaceum Boud.; 44 & Hongo de molle & OR & Talo entero & $\begin{array}{l}\text { Hongo-velador, } \\
\text { decoración de } \\
\text { vivienda }\end{array}$ \\
\hline \multicolumn{5}{|l|}{ GEASTRACEAE } \\
\hline Myriostoma coliforme (Dicks.) Corda; 51 & Polvillo del diablo & MED, VET & Gleba & Cicatrizante \\
\hline \multicolumn{5}{|l|}{ PARMELIACEAE } \\
\hline Usnea amblyoclada Müll. Arg.; 27, 59 & Barba de piedra & MED, VET, TI & Talo entero & $\begin{array}{l}\text { Desinfectante, tintura, } \\
\text { diurético, digestivo }\end{array}$ \\
\hline Usnea angulata Ach.; 63 & Barba de piedra & MED, VET, TI & Talo entero & $\begin{array}{l}\text { Desinfectante, tintura, } \\
\text { diurético, digestivo }\end{array}$ \\
\hline \multicolumn{5}{|l|}{ SCLERODERMATACEAE } \\
\hline Scleroderma bovista Fr.; 45 & Polvillo del diablo & MED, VET & Gleba & Cicatrizante \\
\hline \multicolumn{5}{|l|}{ SUILLACEAE } \\
\hline $\begin{array}{l}\text { Suillus granulatus (L.) Roussel; } \\
26,31,32,35,46,47,50\end{array}$ & Hongo de pino & $A L$ & Talo entero & Alimentación, venta \\
\hline
\end{tabular}

cunninghamii, Calvatia cyathiformis, Calvatia fragilis, Disciseda candida, Mycenastrum corium, Myriostoma coliforme y Scleroderma bovista. Las primeras dos especies son líquenes denominados "barba de piedra", mientras que las siete últimas son hongos gasteroides llamados "polvillo del diablo". Cada una de las especies científicas que poseen un mismo nombre criollo se utiliza de la misma manera y para los mismos fines (Tabla 1).

\section{Las "barba de piedra"}

La recolección de "barba de piedra" (Fig. 3F) es una actividad que se puede realizar en cualquier momento del año ya sea para la venta o para el uso en el hogar. Estas especies son utilizadas para subsanar numerosos malestares y enfermedades (la recetan incluso los/as curanderos/as de la zona), y prácticamente no ha sido sustituida por otras alternativas de la biomedicina. Por todo ello son muy valoradas y su empleo está ampliamente difundido. El uso medicinal de especies del género Usnea ha sido citado también en numerosas comunidades criollas e indígenas del país (Martínez \& Planchuelo, 2003; Martínez, 2010; Arias Toledo, 2006; Scarpa, 2012, 2013; Trillo et al., 2010; Furlan et al., 2011; Suárez, 2014) y del mundo (Illana Esteban, 2012). Asimismo, en correlación con muchos de sus usos vernáculos, sendas pruebas de laboratorio sobre extractos de Usnea spp. han permitido verificar un efecto inhibitorio sobre la actividad bacteriana de ciertas cepas que afectan a humanos (Shukla et al., 2010; Wendakoon et al., 2012; Maharjan \& Baral, 2013). 


\section{Flamini et al. - Hongos útiles y tóxicos según los yuyeros de La Paz y Loma Bola}

Las "barba de piedra" se emplean para limpieza y desinfección de heridas, para aliviar dolores de garganta y muelas, para curar la disfonía y para otros trastornos del sistema respiratorio en general (flema, tos, anginas); dichos usos se sustentan en el efecto desinfectante que los campesinos le atribuyen porque, según explican, el liquen posee altas concentraciones de yodo [en la bibliografía consultada se constata la presencia de ácido úsnico en estas especies, el cual posee efectos antibióticos (Illana Esteban, 2012; Rodríguez \& Estrabou, 2008)]. Salvo para tratar heridas, el modo de empleo más difundido consiste en hacer gárgaras al menos dos veces por día con una infusión aún tibia de 2-3 talos y sal, en una taza de té. Algunos entrevistados le adjudican además propiedades diuréticas que tendrían un efecto de limpieza en los riñones (i.e. desintoxicación de los riñones, asociado o no a síntomas como dolor de cabeza, dolor lumbar, fatiga, entre otros). En estos casos el brebaje se ingiere. Puede ser utilizada por cualquier persona sin restricciones de edad, género, gravidez, etc., pero sí suelen variar las concentraciones y algunos agregados (p. ej. para niños se emplean solo 1-2 talos para una taza).

Para limpiar y desinfectar heridas se realiza una decocción de 1-5 talos en 2-3 tazas de agua y sal, una vez templada la preparación, se lava la zona afectada repitiendo el proceso varias veces por día. Para contrarrestar dolores e infecciones de muelas, a diferencia de la otra modalidad, se agregan los talos cuando el agua llega al punto de hervor y se deja hirviendo entre tres y cinco minutos. Para limpiar y desinfectar heridas se vierte la preparación a temperatura ambiente directamente sobre la zona sentida y se limpia con una gasa o un trapo; se puede repetir la operación todas las veces que haga falta hasta que la herida quede impoluta. Se puede volver a colocar horas después pero siempre se debe limpiar y secar con una gasa y, en caso de ser posible, dejar la herida al descubierto para que se airee. Para aliviar dolores o infecciones en las muelas se realizan buches con el líquido aún tibio y luego se escupe. El proceso se debe repetir al menos dos veces y el tratamiento se debe prolongar hasta que desaparezca el malestar.

Aunque fueron citados solamente por un entrevistado, las "barba de piedra" tendrían dos usos medicinales más: uno para aclarar la garganta antes de cantar, y el otro para aliviar dolores de riñones (efecto analgésico para dolores lumbares asociados a trastornos renales). Para esta última afección se emplea particularmente una mezcla de hierbas que incluye "barba de piedra", "palo azul' (Cyclolepis genistoides D. Don, Asteraceae), 'cola de caballo' (Equisetum giganteum L., Equisetaceae), 'enebro' (Juniperus communis L., Cupressaceae) y 'uva ursi' (Arctostaphylos uva-ursi (L.) Spreng., Ericaceae). El entrevistado destaca que el ingrediente que verdaderamente tiene ese efecto de alivio en los riñones es el 'palo azul', y los restantes ingredientes -incluida la "barba de piedra"- pueden ser sustituidos por otros, manteniendo siempre la cantidad de ingredientes (cinco).

Otro registro interesante y novedoso es el empleo de las "barba de piedra" como parte de una preparación -"la mezcla de los 7 o 9 yuyos"- de efectos positivos para la salud: hace bien tomarla / es muy buena digestiva / es buena para el estómago, y que además tiene un sabor agradable. Esta mezcla es un remedio de tipo panacea: con esa mezcla se puede curar casi cualquier cosa. Lleva 7 o 9 ingredientes y se prepara como infusión (té o mezcladas con mate). Es a base de 'boldo' (Croton serratifolius Baill o Croton hirtus L'Hér, Euphorbiaceae), y puede contener 'cola de caballo' (Equisetum giganteum), cáscara de 'naranja' (Citrus sinensis (L.) Osbeck, Rutaceae), 'poleo' (Lippia sp., Verbenaceae), 'yerba del sapo' (Marrubium vulgare L., Lamiaceae), 'salvia lora' (Buddleja cordobensis Griseb., Scrophulariaceae), 'llantén' (Plantago sp., Plantaginaceae) y "barba de piedra" (Usnea spp.), entre otros posibles ingredientes; es preciso aclarar que el repertorio de posibles ingredientes es finito y generalmente se repiten los mismos componentes.

Cualesquiera sean los ingredientes utilizados, y al igual que lo descripto más arriba para el dolor de riñones, se debe respetar por sobre todo el número de ingredientes, por tanto, el efecto curativo involucra no sólo los principios activos de las plantas sino también principios mágicos y simbólicos. Sobre este aspecto, Martínez \& Planchuelo (2003), quienes también trabajaron con campesinos criollos de la provincia de Córdoba, hablan de "números potentes" que se configuran como una fuerza terapéutica más. Estos números son principalmente impares, usualmente el tres, el siete o el nueve. Por su parte, Arias Toledo (2006), trabajando también con criollos cordobeses, encontró resultados similares sobre un "té de los 
siete yuyos", en el que se destaca nuevamente el valor simbólico del número siete y su poder curativo. Lo mismo encontró Scarpa (2012) entre los criollos del oeste formoseño, para quienes $3 \mathrm{o}$ 7 son los números de ingredientes apropiados en variadas recetas medicinales, asociándolo también a la potencia de estos números para la religión cristiana. En definitiva, aunque el uso de "barba de piedra" en esta preparación es opcional, es el primer registro de un hongo como parte integrante de esta medicina tan importante a nivel local y regional, cuyas connotaciones simbólicas resaltan aún más la trascendencia de las especies de líquenes registradas en el sistema medicinal de los serranos cordobeses.

La "barba de piedra" se encuentra distribuida, mayormente, en áreas alejadas de los poblados por lo que la recolección es realizada sobre todo por los habitantes de las zonas altas de la sierra. Bajan en caballos cargados con bolsas de nylon llenas con "barba de piedra" para venderlas en herboristerías y acopiadoras, y también para compartir con familiares y amigos. Los yuyeros de Loma Bola que viven más cercanos a los montes serranos también salen a recolectarlas pero con menor frecuencia, y en general sólo ante una necesidad puntual o un encargo de algún comerciante. Suelen salir a pie, temprano por la mañana, y se aprovecha el recorrido para recolectar otras hierbas; pocas veces se recolecta exclusivamente "barba de piedra". Las hierbas se colocan por separado de las "barba de piedra", ya que estas últimas se venden o utilizan directamente sin secar.

Los precios que se pagan varían mucho de acuerdo a las necesidades y habilidades comerciales de los yuyeros: en el año 2013 los entrevistados recibieron entre $\$ 5$ y $\$ 20$ (pesos argentinos) por cada kilo de "barba de piedra". Para los criollos que no viven en las zonas altas serranas, la "barba de piedra" es uno de los recursos forestales no madereros que más se valora, ya que su recolección requiere mucho esfuerzo y sus usos son variados. Por esto, y debido a los bajos precios que se pagan, la mayoría prefiere recolectar y almacenar para el empleo en el hogar. Sin embargo, en los momentos del año en que hay escasez de alternativas laborales, ante un pedido concreto, salen a recolectar igualmente y reciben el dinero que se les ofrezca.

\section{Los "polvillo del diablo"}

En la práctica, el uso medicinal de los "polvillo del diablo" no se halla muy extendido, incluso entre quienes reafirman sus bondades son pocos los que lo han usado alguna vez. A diferencia de las "barba de piedra", están siendo reemplazados por medicamentos provenientes de la biomedicina. Sin embargo, el conocimiento sobre la utilización y los modos de aplicación sí están muy difundidos. La mayoría mencionó que a pesar de que están presentes en muchos y variados ambientes, se ha dado una merma sustancial en el uso debido a una disminución de estos hongos que podría estar asociada al avance de los procesos de deforestación y modificación del uso del suelo en la zona. A futuro, sería interesante indagar más a fondo sobre esto y si ocurre lo mismo con otras medicinas fúngicas o vegetales silvestres.

El principal empleo es como cicatrizante de heridas y quemaduras ${ }^{6}$ externas. Se utiliza la gleba de los basidiomas maduros: deben estar marrones o negros por fuera, y secos y marrones por dentro. Se aplica directamente la gleba sobre la zona afectada, previa desinfección de la herida. La cantidad es determinada a ojo y depende del tamaño de la herida, pero básicamente se debe cubrir espolvoreando con gleba toda el área lastimada, como si se salara con el polvito. Luego se deja la herida descubierta y se repite la aplicación hasta que cicatrice definitivamente. Explican que el efecto hemostático se debe a que la gleba es secante, seca la herida. Se puede utilizar también en forma de emplasto mezclando gleba con aceite de 'girasol', o colocando primero aceite y encima la gleba. Un dato sobresaliente surgido en las entrevistas es que ante una herida se puede combinar el uso de "barba de piedra" y "polvillo del diablo". Primero se emplea la infusión de "barba de piedra" para limpiar y desinfectar la herida, y luego se aplica "polvillo del diablo" para favorecer la cicatrización; pasadas unas horas se repite el proceso. De esta manera, según explican, se puede prescindir completamente de utilizar medicamentos de origen farmacéutico.

El almacenamiento de "polvillo del diablo" no es habitual entre los yuyeros, pero si lo hacen, suelen acopiar al que consideran el verdadero "polvillo

\footnotetext{
6 En general la gente habla por un lado de heridas y por otro de quemaduras. Si bien las quemaduras podrían ser consideradas heridas desde la perspectiva ética, este último vocablo se emplea localmente para referirse a cortaduras, raspones y otras laceraciones, pero no a quemaduras.
} 


\section{Flamini et al. - Hongos útiles y tóxicos según los yuyeros de La Paz y Loma Bola}

del diablo", Calvatia cyathiformis. Afirman que es el más eficiente y resulta el más práctico de usar porque tira más polvo. Se guarda seco, envuelto con papel dentro de una bolsa, y así se conserva durante meses. En el fundamento del uso de "polvillo del diablo" se puede apreciar claramente la influencia de la medicina humoral hipocrática [para consultar y ampliar sobre esta temática consultar a Foster (1994)], típica en las comunidades campesinas y criollas del país (Idoyaga Molina, 2001; Martínez \& Planchuelo, 2003; Scarpa, 2012; Martínez, 2010). La gleba es considerada cicatrizante porque deseca heridas (que representan humedad), es decir responden a las nociones del equilibrio húmedo y seco: ante un problema húmedo se aplica un remedio seco. Asimismo, Scarpa (2012) encontró entre los criollos del oeste de Formosa que especies de Usnea son consideradas "cálidas" y se usan para curar trastornos "frescos". A su vez, encontró que los problemas en las vías respiratorias corresponden a dolencias de índole "fresca", por lo cual es muy probable que el uso de "barba de piedra" entre los yuyeros para ese tipo de problemas (es utilizada tibia o caliente), también responda a la teoría humoral hipocrática.

\section{Veterinarios, medicinas para los animales}

Las mismas especies que se emplean en medicina humana fueron también registradas por su utilidad en veterinaria. El uso veterinario de las "barba de piedra" y de los "polvillo del diablo" no es comúnmente practicado en la actualidad, aunque el conocimiento sobre las maneras de preparación y aplicación sí están muy difundidas. Esta disminución podría tener su razón en que ningún entrevistado posee actualmente ganado propio y la única posibilidad de aplicar estas medicinas es en sus trabajos cuidando ganado ajeno, pero en cuyo caso los dueños de los animales prefieren utilizar la biomedicina veterinaria.

Las "barba de piedra" se utilizan para la limpieza de heridas externas y los "polvillo del diablo" se usan como cicatrizantes, en ambos casos sobre todo a caballos y vacas. Los modos de uso son los mismos que los descriptos para humanos, sólo que se debe administrar mayor cantidad y en mayor concentración para que penetre bien y haga efecto, debido a que la piel de los animales, comentan, es más gruesa. Las proporciones son determinadas a ojo; estiman que para un caballo o una vaca son necesarios uno o dos puñados de talos en un litro de agua, que deben hervir al menos durante cinco minutos. Se aplica mínimamente dos veces en el mismo día en que ocurrió la herida. También sirve para quemaduras.

No se han encontrado referencias sobre el empleo de Usnea spp. en la bibliografía consultada. Sin embargo, no sería extraño que esta práctica también sea llevada a cabo por criollos y/o indígenas de otras partes del país, ya que sí existe información sobre el uso de especies de Usnea como desinfectante aplicado a personas (Furlan et al., 2011). Por el contrario, el uso de Calvatia fragilis y Battarrea phalloides (Dicks.) Pers. fue registrado entre los criollos del Noroeste argentino (Scarpa, 2012) y el de Calvatia cyathiformis entre criollos de las sierras de Córdoba (Martínez \& Lujan, 2011), todas utilizadas como cicatrizantes de heridas externas en animales; de estas tres especies, las dos del género Calvatia también fueron consignadas en esta investigación para los mismos fines. Como aportes originales de uso veterinario de hongos en el país se encuentran las siguientes cinco especies: Bovista cunninghamii, Disciseda candida, Mycenastrum corium, Myriostoma coliforme, Scleroderma bovista.

En todas las modalidades de uso veterinario de "polvillo del diablo", al igual que sucede en la medicina humana de los yuyeros, se puede apreciar nuevamente la influencia de la medicina humoral hipocrática en las prácticas de curación. En consonancia con esto, dada las notorias coincidencias en los modos de uso y preparación entre la medicina humana y animal, queda a la vista que separarlas no es del todo adecuado desde la perspectiva émica, y tal como propone Scarpa (2012) para los criollos formoseños, la medicina tradicional veterinaria de los yuyeros forma parte de un sistema médico más amplio, que cuenta con un altísimo grado de coincidencias con los conocimientos y prácticas médicas aplicadas a personas en lo que a criterios terapéuticos, especies utilizadas y modos de preparación y aplicación respecta.

\section{Hongos que tiñen}

Entre los yuyeros, la tinción, el hilado y la confección de tejidos (de lana de oveja o de hilo de algodón industrial) son tareas casi íntegramente femeninas. Desde niñas, al tiempo que colaboran y acompañan a las mujeres adultas, se introducen 
en el oficio. Los pormenores de la práctica de tinción de textiles entre criollos de Argentina han sido referidos por varios autores (Trillo \& Demaio, 2007; Guerrero Maldonado, 2008; Keller, 2010; Palacio et al., 2011; Suárez \& Arenas, 2012). Se mencionarán aquí solamente detalles disímiles o importantes para nuestros objetivos.

Por lo general las materias primas utilizadas para teñir son especies vegetales de la zona, así como anilinas compradas en los poblados. Estas últimas son las preferidas porque son económicas, facilitan el trabajo y permiten una gran diversidad de colores. Todas las mujeres entrevistadas han teñido con tintes naturales y así continúan haciéndolo. En lo que respecta a los hongos, emplean líquenes para tal fin (Usnea amblyoclada y $U$. angulata). La búsqueda de hongos tintóreos siempre se realiza aprovechando las habituales salidas al campo para la recolección de hierbas silvestres medicinales. Sólo se recoge la cantidad de "barba de piedra" necesaria debido a la dificultad para encontrarlas y el esfuerzo extra que equivale.

El líquido de tinción se prepara en ollas de aluminio, de uso exclusivo para este fin. Se coloca la olla con agua al fuego usando leñas fuertes ('chilca', Flourensia oolepis S.F. Blake, Asteraceae; 'molle', Lithraea molleoides; 'espinillo', Acacia caven (Molina) Molina, Fabaceae). Luego que el agua hierve unos minutos, se agregan los talos y el mordiente (sal gruesa o alumbre), se deja hirviendo durante una hora y cada tanto se remueve con un palo, luego se retira del fuego y se deja reposar por 24hs aproximadamente. Posteriormente se calienta el líquido y se agrega el textil (hilado o sin hilar) y se deja alrededor de una hora o más, removiendo de vez en cuando. Por último, se retira la olla del fuego y se deja reposar toda la preparación por 24hs. Cuando se emplea lana hilada o hilos de algodón, antes de llevarlos a la olla se debe colar el líquido para que no se adhieran restos de material al hilo.

Las proporciones de hongos tintóreos y textil, así como el tiempo que debe permanecer la lana con las sustancias tintóreas, se determinan a ojo de acuerdo a los colores que se buscan, y dependen de la experiencia de cada persona. Sin embargo, una de las entrevistadas explicó que para la tinción de una olla de cinco litros de capacidad, llena de lana, se necesitan aproximadamente 100 gramos de "barba de piedra" seca y dos cucharadas soperas de mordiente. Con esas medidas se obtiene lana de color marrón claro o amarillo. Una vez que la lana está teñida, se retira de la olla y se deja secar al sol. Si se usó lana sin hilar, luego que secó se realiza el tizado y finalmente el hilado con ayuda de un huso con tortero (Fig. 2D). De acuerdo a las entrevistadas es muy difícil obtener dos veces el mismo color debido a que cada talo individual cuenta con distintas cualidades tintóreas. Se puede mezclar la "barba de piedra" con otras plantas para obtener variaciones en los colores (diferentes tonalidades de amarillo y marrón).

La tinción de productos textiles con hongos ya ha sido registrada entre criollos e indígenas en nuestro país (Guerrero Maldonado, 2008; Keller, 2010), incluso también con especies del género Usnea (Trillo \& Demaio, 2007; Palacio et al., 2011; Suárez \& Arenas, 2012). Por otro lado, llama la atención la amplia variedad de colores que se pueden obtener de las distintas especies de Usnea. Palacio et al. (2011), por ejemplo, encontraron que en algunas comunidades de Santiago del Estero se utilizaban ejemplares de Usnea spp. para obtener colores rojizos; según Suárez \& Arenas (2012) la decocción de talos completos de Usnea alata Motyka produce tintes de color verde, marrón rojizo y tonos entre amarillo y anaranjado; Trillo \& Demaio (2007) muestran que con Usnea amblyoclada se pueden obtener distintos colores, incluyendo distintas tonalidades de amarillo, anaranjado y marrón. Los resultados de los últimos dos artículos mencionados coinciden con lo que se registró en este trabajo con $U$. amblyoclada y $U$. angulata.

Los tejidos o las madejas de lana ovina hilada se venden por encargo y por lo general son trabajos esporádicos y aislados. Los tejidos que más se confeccionan y demandan son alfombras de pequeñas dimensiones, alforjas, aperos, fajas y cobijas. Los trabajos de tinciones con vegetales $\mathrm{u}$ hongos son mejor pagados que aquellos realizados con anilinas. A su vez, los entrevistados afirman que las tinciones con productos naturales son de mejor calidad: el color persiste más tiempo y se desgasta menos. En este sentido, aunque la tinción con anilinas es más rápida y permite obtener colores brillantes y variados, últimamente ha aumentado la demanda de productos artesanales teñidos con vegetales u hongos en la zona, lo cual a su vez ha incrementado e incentivado su elaboración. 


\section{Flamini et al. - Hongos útiles y tóxicos según los yuyeros de La Paz y Loma Bola}

\section{Alimenticios, hongos que se comen}

Se registraron dos especies de hongos silvestres alimenticios: Phlebopus bruchii y Suillus granulatus. Ambas son recolectadas y utilizadas tanto para la venta como para la alimentación de la propia familia. La cosecha de estos hongos no es una actividad prioritaria ya que la recolección de plantas medicinales es la principal tarea que desarrollan los yuyeros a lo largo de todo el año. Son pocos los que salen a juntar exclusivamente hongos, la mayoría aprovecha las salidas de recolección de plantas medicinales. Se realiza entre los meses de diciembre y abril, época en la que emergen los basidiomas, y por lo general uno, dos o hasta tres días después de una lluvia porque si no se pasan y no sirven. En ocasiones lo hacen a caballo, pero lo habitual es ir a pie. Las salidas para recolectar P. bruchii consisten en largas caminatas de dos o tres horas de duración por zonas boscosas y de pendiente marcada, y en ocasiones atravesando quebradas y terrenos muy escarpados. De esta forma, cada entrevistado visita diversos lugares del bosque serrano en búsqueda de $P$. bruchii; por lo general se buscan molladas (bosquecillos de Lithraea molleoides) o árboles de 'coco' (Zanthoxylum coco), debido a que consideran que existe un tipo de asociación particular, a veces directa a veces indirecta, en la distribución del hongo con esos árboles ${ }^{7}$. Cuando se llega a una zona de 'cocos' o a una mollada, se alejan del camino para buscar los hongos debido a que, por un lado, otras personas recorren esos mismos caminos y es muy probable que alguien ya haya recogido allí, y en segunda instancia porque consideran que crecen próximos entre sí, entonces, al hallar un basidioma, se examina cuidadosamente el terreno adyacente en busca de otros basidiomas: donde hay uno siempre hay más.

La búsqueda de $S$. granulatus se realiza en propiedades privadas forestadas con 'pinos' (Pinus halepensis Mill., Pinaceae) donde habitualmente vive alguna familia que cumple el rol de cuidadora (muchas veces son campesinos), que también salen a recolectar hongos, de modo que son ellos los que tienen prioridad en esas zonas (Fig. 2C).

\footnotetext{
7 Para más información sobre el tipo de vínculo y otros conocimientos de estos hongos con las especies arbóreas mencionadas, se recomienda consultar el trabajo de Flamini et al. (2015).
}

En estos casos, los recorridos son más cortos y las salidas más frecuentes. Según la opinión de los entrevistados los "hongos de pino" son más fáciles de aparecer y se encuentran en mayor cantidad que P. bruchii.

Por lo general los yuyeros saben de antemano qué lugares visitar: van a buscar hongos a zonas en los que ya han encontrado anteriormente, incluso cruzando alambrados. El aumento de campos alambrados fue citado por los entrevistados como la principal causa de la disminución en la recolección de hongos y plantas silvestres de los últimos años.

Las mujeres adultas salen acompañadas por sus hijos/as, en tanto que los varones generalmente lo hacen solos. Son entonces las madres quienes principalmente transmiten el conocimiento sobre la recolección de hongos. Otra forma de transmisión del conocimiento es observando trabajar a amigos o compañeros. Esta modalidad se cumple, principalmente, entre quienes nacieron y vivieron en las zonas más altas de las sierras ya que en esos lugares no crecen hongos comestibles, por lo que su primer contacto es cuando se mudan más abajo. En otras investigaciones realizadas en el país con grupos indígenas, y que incluyen datos sobre hongos alimenticios, se destaca la fuerte raigambre de la actividad en cada una de esas comunidades (Ladio \& Lozada, 2000; Domínguez Díaz, 2010). El caso de los yuyeros es similar pero un poco más heterogéneo. Se registraron testimonios de personas nacidas durante la década de 1940, que alegan que ya sus padres recolectaban Phlebopus bruchii para su propia alimentación; incluso una entrevistada nacida en 1939 recordaba salir, durante su niñez, junto con sus abuelos a juntar "hongos de coco". Sin embargo, todos estos registros corresponden a personas nacidas en las zonas de menor altitud. Entonces, para algunos la recolección de hongos comestibles cuenta con una muy rica historia, mientras que para otros (los originarios de las áreas alto serranas) es mucho más reciente pero no menos importante.

Por otra parte, la recolección de $S$. granulatus es bastante más reciente para todos los campesinos: estos hongos crecen asociados a Pinus spp. (todas son especies exóticas), por lo que, dado que las primeras plantaciones en la zona sucedieron durante la década de 1950 (Izurieta et al., 1993), el vínculo no supera los cincuenta años. Esto podría ser uno de los fundamentos que justifique 
el rechazo generalizado que tienen hacia el consumo de esta especie, a diferencia de $P$. bruchii que es más aceptada y mejor valorada en términos generales, ya que es una especie nativa que crece asociada a dos especies de árboles también nativos de la zona y que los yuyeros conocen muy bien.

Al ser consultados por la aparición de hongos silvestres alimenticios, los entrevistados comentaron que necesitan de la humedad que se puede acumular en la tierra o en las raíces de determinadas especies de árboles ('cocos', 'molles' o 'pinos'), es decir que salen con más facilidad en lugares sombríos y húmedos como los bosques y en las cercanías a ríos y arroyos, y allí van a buscarlos. En este sentido, dos entrevistados plantearon que la relación que mantienen los "hongos de comer" con los árboles bajo los que crecen, es similar a la de un fruto y el árbol que lo produce: el hongo es como la fruta del palo. La diferencia con los verdaderos frutos del árbol, explican, es que hongos y árboles son considerados dos tipos de organismos distintos donde uno, el árbol, hace posible el desarrollo del otro, el hongo.

Para el encuentro y reconocimiento de los hongos silvestres alimenticios es fundamental poseer una vista bien adiestrada para poder localizar hongos mimetizados con su entorno, entremezclados y escondidos entre la hojarasca y poder distinguirlos de otros hongos. Sin embargo, algunos entrevistados fueron capaces de reconocer hongos, que se encontraban secos y enteros o picados, por el olor más que por su aspecto. De esa forma, pudieron diferenciar ejemplares de hongos alimenticios de otros que no lo eran, y hasta distinguir entre pedazos secos de P. bruchii de otros de $S$. granulatus. En otras palabras, el olfato también es un sentido que se emplea y debe estar igualmente preparado. Los criterios para saber cuáles son las especies comestibles y la diferenciación entre ellas son variados, pero mayormente tienen que ver con particularidades morfológicas perceptibles a simple vista. Entre las principales destacan:

- Color de la superficie del píleo: marrón oscuro en $P$. bruchii y amarillo o marrón más claro para $S$. granulatus.

- El color de la superficie del himenóforo: es únicamente marrón o amarillo en los comestibles.

- Tipo de himenóforo de los hongos silvestres alimenticios: es todo parejo con huequitos, como una esponja (himenóforo poroide).
- Los "hongos de coco" son más oscuros y más grandes que los "hongos de pino".

Determinados ejemplares de las especies alimenticias no son recogidos cuando están negros o cuando tienen lo que los yuyeros llaman el mojo (moho). Incluso si son juntados por error y se ponen en contacto con otros hongos, estos también pueden arruinarse o hacerse agua (estado de pudrición o degradación avanzado). Tampoco son recogidos aquellos hongos que están dañados, o que hayan sido comidos por 'hormigas', o cuando al recogerlos se encuentran con 'bichitos bolita' ${ }^{8}$ debajo del píleo.

Las herramientas y elementos básicos que se llevan en cada salida son recipientes para acarreo, cuchillo y machete. Los recipientes que se usan son canastos de 'mimbre' (Salix fragilis L., Salicaceae) o de paja, bolsos, bolsas de nylon o bolsas de plástico tejido. De todos ellos, se recomienda usar los canastos porque así los hongos se airean y no se golpean o aplastan tanto.

El modo de recolección consiste en tomar directamente con la mano la parte basal del pie del hongo, procurando que el basidioma salga completo; algunos los sacan con ayuda de un cuchillo hundiéndolo en la tierra para sacar todo el cuerpo fructífero y otros cortan con un cuchillo el pie dejando parte del basidioma enterrado. Para $S$. granulatus se debe prestar especial atención ya que consideran que es frágil. Los colocan en el recipiente de acarreo acomodados con el pie hacia arriba, y procurando no amontonarlos ni apretarlos. Cuando además se sale a buscar plantas, éstas se colocan por separado de los hongos para no dañarlos. La cantidad que se recolecta en cada viaje depende de lo que haya disponible pero por lo general un máximo de unos 8 o 10 kilos por persona. Debido a las diferencias en los sustratos y las distribuciones de $P$. bruchii y $S$. granulatus, nunca se juntan en un mismo viaje, se colecta uno u otro.

Ya de regreso al hogar los hongos se sacan inmediatamente del recipiente y se colocan dispersos sobre alguna superficie limpia y seca. Este paso es muy importante porque de acuerdo a los testimonios recogidos si son dejados en el mismo recipiente todo el día se pueden echar a perder.

El proceso de secado resulta fundamental para lograr el almacenamiento a largo plazo. Se deben

\footnotetext{
${ }^{8}$ Artrópodos del suborden Oniscidea.
} 


\section{Flamini et al. - Hongos útiles y tóxicos según los yuyeros de La Paz y Loma Bola}

cortar en rodajas longitudinales de un mínimo de $2 \mathrm{~cm}$ de espesor aproximadamente a $S$. granulatus (Fig. 2B), y un poco más pequeñas a $P$. bruchii. La diferencia, sostienen, se debe a que el primero tiene más agua y menos cuerpo o sustancia, entonces se seca más rápido y disminuye más su tamaño. Cuando se realiza el corte se debe procurar que el estípite no quede intacto porque de lo contrario el secado es más lento, de todas formas, el tamaño de corte es estipulado en base a las exigencias de los comerciantes que los compran. Si los hongos son para su propia alimentación no importa el tamaño. Deben ubicarse sin amontonar al sol, variando la duración según las condiciones climáticas. Las superficies utilizadas para el secado son: madera, zarzo de 'cañas' o de 'mimbre', cartón, cama elástica, lona, diario y chapa de zinc.

Durante el proceso de secado no se deben mojar porque se hacen agua o amojosan y se arruinan, de modo que si llueve se deben poner a cubierto. Por el mismo motivo, una recomendación adicional es entrarlos a la casa o taparlos durante la noche para evitar el rocío y la humedad. Se calcula que por cada diez kilogramos de "hongos de pino" frescos se obtiene $1 \mathrm{~kg}$ de hongos secos, mientras que del "hongo de coco" se pueden obtener $2 \mathrm{~kg}$. Una vez secos se almacenan en bolsas de nylon o de papel, siendo estas últimas las más recomendadas al menos durante los primeros días. Los hongos son conservados en la heladera o a temperatura ambiente dentro de la casa, hasta que se llega a acumular una cierta cantidad para entonces ser vendidos. Una recomendación habitual de los yuyeros para evitar que los hongos se apolillen (que sean comidos por 'polillas'9 u otros insectos), es colocar en el recipiente donde se los conserva algunas hojas de 'laurel' (Laurus nobilis L., Lauraceae).

Sólo un entrevistado utiliza las dos especies de hongos alimenticios, mientras que los demás colaboradores que consumen hongos preparan comidas exclusivamente con $P$. bruchii. La mayoría considera que los "hongos de coco/molle" son mejor alimento que los "hongos de pino" porque el árbol (al que se asocian) es mejor, y por eso (los hongos) tienen más sustancia. Se recopilaron 6 recetas o formas de preparación: tuco de hongos secos para pastas, hongos secos fritos con huevo, estofados

\footnotetext{
${ }^{9}$ Orden Lepidoptera, especie no identificada.
}

con hongos secos, hongos secos en guiso de arroz o de fideos, milanesas de hongos frescos y hongos secos o frescos en escabeche. Para cualquiera de estas recetas, se pueden utilizar hongos frescos a los que, antes de poner a cocinar, se les retira la cutícula y/o la barba (estrato de tubos del himenóforo). La preparación más utilizada a partir de hongos secos es el tuco para pastas, mientras que los hongos frescos suelen prepararse sofreídos con cebolla (Allium cepa L., Amaryllidaceae), ajo (Allium sativum L., Amaryllidaceae), carne bovina y huevo. Muchos consideraron que los hongos alimenticios son de un alto valor nutricional y los mencionaron como un sustituto de la carne, un entrevistado incluso comentó que como es de la tierra es mejor alimento que la carne.

La recolección de hongos alimenticios se realiza, principalmente, con la intención de obtener réditos económicos. Aunque no es la actividad económica primaria, ayuda mucho en las economías familiares, sobre todo entre mediados de febrero y abril, cuando se terminan los trabajos vinculados al turismo. La mayoría de los entrevistados reconoció que cada vez se sale con menor frecuencia a juntar hongos porque se encuentra cada vez menor cantidad. En este sentido, destacan que en los últimos 10 años se ha registrado una merma muy significativa de lluvias, lo que resulta condicionante para la aparición de los cuerpos fructíferos, lo cual, sumado a la deforestación de los bosques serranos y al alambrado y privatización de los campos, afecta considerablemente la actividad de recolección no sólo de hongos sino también de plantas, trabajos que son el sostén económico de numerosas familias.

Son los yuyeros quienes van a ofertar los hongos a los comercios, aunque en algunas ocasiones también les realizan encargos particulares. A excepción del Hotel Loma Bola, que también compra hongos frescos, todos los comerciantes compran exclusivamente hongos deshidratados. Los lugares de compra principales son herboristerías y almacenes de Loma Bola y La Paz, y dos hoteles de Loma Bola. Uno de los entrevistados tiene la posibilidad de trasladarse hasta la localidad de Merlo (provincia de San Luis), donde puede vender los mismos productos a mejores precios.

Los precios varían año a año y de acuerdo a la disponibilidad, es decir, el precio aumenta después de abril debido a la finalización de la temporada de hongos. Asimismo, aunque existe cierta uniformidad 
en los precios, los comerciantes son quienes los establecen, por lo que también se paga de acuerdo a las habilidades individuales y urgencias económicas de cada yuyero. Prueba de ello es la variación del precio registrado durante abril de 2013: en algunos establecimientos se pagaba $\$ 10$ por el kilo de "hongo de pino" o "de coco" fresco y $\$ 40$ por el kilo de hongo seco, mientras que en otros se pagaba entre $\$ 120$ y $\$ 150$ el kilo de "hongo de coco" seco; en Merlo algunos negocios pagaban hasta $\$ 300$ el kilo de "hongo de coco" seco (fraccionado en paquetes de 100 gramos), con un piso mínimo de \$200 el kilo.

Comparativamente, el precio que se paga por el kilo de hongos es en promedio varias veces superior al que se paga por el kilo de 'peperina' [Minthostachys verticillata (Griseb.) Epling, Lamiaceae], que es la hierba silvestre de mayor precio entre todas las que juntan los yuyeros (en marzo de 2013 se pagaba entre 30 y 50 pesos por kilo seco y picado). Las cantidades de hongos recolectados en cada año varían según una multiplicidad de factores (vide supra). De todas maneras, podemos tener una primera idea de los montos anuales que se pueden conseguir tomando como ejemplo el caso de un informante, que reveló que entre los meses de diciembre de 2012 y febrero de 2013 pudo recolectar aproximadamente $3 \mathrm{~kg}$ de Phlebopus bruchii (peso ya deshidratado), y considerando que consigue venderlos en Merlo a un precio de entre doscientos y trescientos pesos argentinos por kilo, la extrapolación daría una suma de entre seiscientos y novecientos pesos en ese lapso, sólo por P. bruchii. Vale la pena destacar, que de acuerdo a éste y a otros entrevistados el verano de 2012/2013 fue muy seco, por lo que la recolección no fue buena. Teniendo esto en cuenta, y que en ese momento la temporada aún no terminaba (se puede prolongar hasta abril inclusive), se podría considerar que esos valores son un piso mínimo del aporte económico de la temporada de tan sólo una de las especies que se recolectan para la venta. En conclusión, económicamente, la ventaja de la venta de hongos radica en el hecho que, si bien es un recurso que depende de múltiples factores ambientales que lo convierten en un recurso inestable aún durante la temporada, se obtiene una gran cantidad de dinero en poco tiempo y que en el caso de secarlos, se pueden almacenar y vender en momentos del año que el trabajo escasee.
Hoy en día la recolección de hongos está más enfocada a la venta, pero antiguamente sólo se usaban para consumo en el hogar. De acuerdo a algunos entrevistados la venta de hongos comenzó hace aproximadamente unos sesenta años (cuando el turismo cobró mayor trascendencia en la zona), y tomó más énfasis con el auge del comercio de hierbas silvestres medicinales. En la actualidad, por el precio y la escasez se han convertido en un artículo de lujo para los campesinos, y aún cuando reconocen su alto valor nutricional y en algunos casos aprecian su sabor, hoy prefieren venderlos. Esto último contrasta con lo registrado en distintas culturas del mundo, como en comunidades mestizas mexicanas (Ruán Soto et al., 2009), en comunidades indígenas de Camerún (van Dijk et al., 2003) y Nigeria (Okigbo \& Nwatu, 2015) o entre los sherpas nepaleses (Giri \& Rana, 2008), que consideran a los hongos como un sustituto más económico de la carne.

\section{Ornamental, hongo decorativo}

Fueron descriptas tres modalidades de uso ornamental para Ganoderma resinaceum: un velador de madera al que se le adhirió un basidioma seco, el uso como elemento decorativo en el patio y para decoración en el interior de la vivienda.

El hongo-velador observado está conformado por una base de madera de 'espinillo' (Acacia caven) con forma piramidal, fijada a una columna también de la misma madera, engrosada en el centro. Termina en una pantalla que cubre el foco. En la columna de la lámpara está adherido el píleo de un ejemplar de G. resinaceum que tiene un diámetro de $20 \mathrm{~cm}$ aproximadamente (Fig. 2E). En el interior de una vivienda se observó un ejemplar de G. resinaceum seco colocado sobre una repisa a modo de decoración. En el patio de otra vivienda, sobre un árbol adulto de 'molle' (Lithraea molleoides), han surgido sucesivos basidiomas de G. resinaceum. En el seno de la familia consideran que, por su combinación de colores, tamaño y aspecto brillante como si estuviera barnizado (por la laca del píleo), el hongo posee una particular belleza y hace que el árbol esté más lindo. Tal es el valor que le asignan a esta especie que, para que sigan apareciendo, riegan la base del tronco donde ya se han desarrollado basidiomas, y le quitan las malezas y basura a su alrededor para que quede mejor expuesto. 


\section{Flamini et al. - Hongos útiles y tóxicos según los yuyeros de La Paz y Loma Bola}

\section{Recapitulación y comentarios finales}

Los resultados de este trabajo muestran que los hongos lejos de ser ignorados o desconocidos por los pobladores locales, ocupan un lugar destacado en sus vidas y que muchas de las aplicaciones registradas son importantes en distintos ámbitos de su cultura (medicina, veterinaria, alimentación, textil, decoración y podría agregarse comercio). De las 32 especies estudiadas, el $37,5 \%$ tiene alguna utilidad práctica en la vida cotidiana de la gente local, y en general la mayoría de las especies útiles sirven para más de una finalidad. Las categorías de uso medicinales y veterinarios son las que más especies involucran (9 cada una) (Fig. 4), pero aunque las formas de tratamiento y dosis difieren, se trata de las mismas 9 especies que además sirven para fines o propósitos similares. Por otro lado, a juzgar por los resultados obtenidos, podríamos afirmar que los hongos alimenticios a pesar de ser solamente dos especies, ocupan un rol fundamental para la economía de muchas familias y quizás por ello son de los más relevantes para su vida cotidiana.

El análisis de los resultados obtenidos en conjunto con aquellos presentados en nuestra contribución anterior (Flamini et al., 2015) indica que la importancia local de los hongos no sólo radica en los distintos usos prácticos que estos poseen; su relevancia excede el nivel utilitario, ya que muchos de los hongos conocidos por los entrevistados no son empleados (20 de 32 estudiados), pero sí son nombrados, observados en detalle y clasificados. De todas formas, teniendo presente los pormenores descriptos para los hongos útiles en contraposición a lo registrado para los demás, pareciera que los yuyeros conocen en mayor detalle y profundidad aquellos hongos que revisten alguna utilidad práctica.

Para terminar, debe destacarse que el conocimiento y entendimiento de los vínculos entre los pobladores locales y los hongos de su entorno resultan clave para contribuir en la elaboración de proyectos de desarrollo local que sean factibles, sustentables y de interés para las comunidades. A ello pretende contribuir este artículo. De igual manera, se espera que los resultados del presente trabajo sean un puntapié para fomentar futuros estudios etnomicológicos en el país en esta y otras sociedades, los cuales resultan urgentes en un contexto en el que la diversidad biocultural, así como saberes y prácticas tradicionales de los pobladores criollos e indígenas de Argentina se encuentran seriamente amenazados.

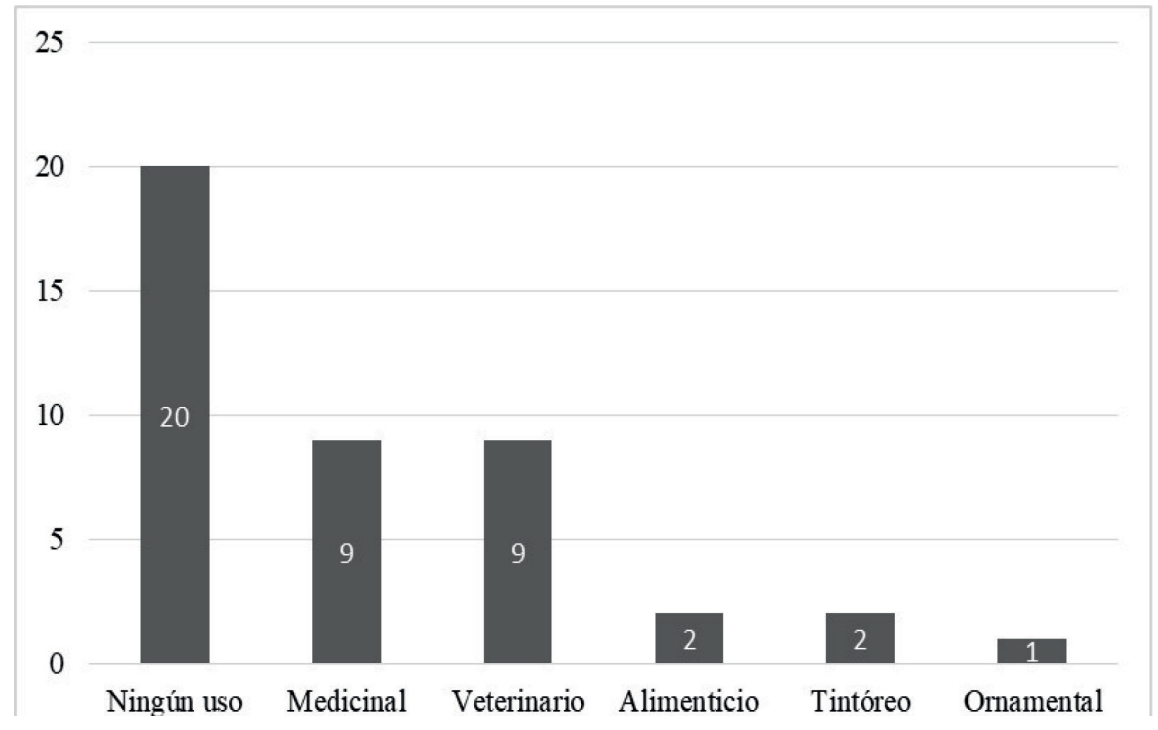

Fig. 4. Número de especies empleadas según categoría de uso. 


\section{Agradecimientos}

A todos los entrevistados que tan gentilmente nos abrieron las puertas de sus casas y compartieron los relatos y conocimientos que hicieron posible este trabajo. A la familia Rintisch por todo el apoyo durante los viajes. A Juan Manuel Rodríguez y Bernardo Lechner por la colaboración desinteresada con la identificación de líquenes y Agaricales respectivamente. Al CONICET y a la ANPCyT, que financiaron parcialmente esta investigación, y a la Universidad Nacional de Córdoba que proveyó espacio, equipamiento y materiales para el mismo.

\section{Bibliografía}

ACOSTA, C. A. 2009. Variedades de vegetales y de hongos existentes en la República Argentina $y$ poseedoras de principios Psicoactivos. Tesis de maestría. Facultad de Ciencias Médicas, Universidad Nacional de Córdoba, Córdoba.

ARAGÓN, R. \& J. M. MORALES. 2003. Species composition and invasion in NW Argentinian secondary forests: Effects of land use history, environment and landscape. J. Veg. Sci.14: 195-204.

ARENAS, P. 2003. Etnografía y alimentación entre los Toba-Nachilamolettek y Wichi-Lhuku'tas del Chaco Central (Argentina). Editor Pastor Arenas, Buenos Aires.

ARENAS, P. \& G. J. MARTÍNEZ. 2012. Estudio etnobotánico en regiones áridas y semiáridas de Argentina y zonas limítrofes. Experiencias y reflexiones metodológicas de un grupo de investigación. En: ARENAS, P. (ed.), Etnobotánica en zonas áridas y semiáridas del Cono Sur de Sudamérica, pp. 11-43. CEFYBO-CONICET, Buenos Aires.

ARIAS TOLEDO, B. 2006. Aspectos cuantitativos, cualitativos y simbólicos de la medicina tradicional de los pobladores criollos de Cerro Colorado (Córdoba, Argentina). PINACO-Investig. Antropol. Cog. 6: 105-115.

ARORA, D. \& G. H. SHEPARD. 2008. Mushrooms and Economic Botany. Econ. Bot. 62: 207-212.

BARRON, G. 1999.Mushrooms of northeast North America: Midwest to New England. Long Pine, Edmonton.

BERNARD, H. R. 2000. Social Research Methods: Qualitative and Quantitative Approaches. SAGE Publications, California.

BOA, E. 2004. Wild edible fungi: a global overview of their use and importance to people. Non-Wood Forest Products 17. FAO, Roma.
BUGUÑA, P. \& C. I. COMETTA (coords.). 2010. Diagnóstico preliminar y formulación de proyectos. Municipalidad de La Paz, Valle de Traslasierra. Provincia de Córdoba, Argentina. Instituto del Ambiente Liliana Rainis. FAUDI-UNC. Disponible en: http://es.scribd.com/doc/45058814/ Diagnostico-La-Paz [Acceso:14-08-2017].

BURK, W. R. 1983. Puffball usages among North American Indians. J. Ethnobiol. 3: 55-62.

CABRERA, A. L. 1971. Regiones fitogeográficas de la República Argentina. Bol. Soc. Argent. Bot. 14: $1-42$.

CHRISTENSEN, M., S. BHATTARAI, S. DEVKOTA, \& H. O. LARSEN. 2008. Collection and use of wild edible fungi in Nepal. Econ. Bot. 62: 12-23.

COETZEE, J. C. \& A. E. VAN WYK. 2009. The genus Calvatia ('Gasteromycetes', Lycoperdaceae): A review of its ethnomycology and biotechnological potential. Afr. J. Biotechnol 8: 6007-6015.

COIRINI, R. \& C. W. ROBLEDO.1999. Elementos de Diagnóstico Rural Rápido. En: CASERMERIO, J. \& E. SPAHN (eds.), Sistemas agroforestales para pequeños productores de zonas húmedas, pp. 158163. Universidad Nacional de Entre Ríos, Entre Ríos.

DESCHAMPS, J. R. 2002. Hongos silvestres comestibles del Mercosur con valor gastronómico. Documento de Trabajo $\mathrm{N}^{\circ} 86$, Universidad de Belgrano. Disponible en: http://repositorio.ub.edu. ar/handle/123456789/433 [Acceso: 12-09-2017].

DOMÍNGUEZ, L. S. \& M. L. HERNÁNDEZ CAFFOT. 2011. Hongos venenosos de Córdoba. Infografía publicada por el Ministerio de ciencia y tecnología del gobierno de la Provincia de Córdoba. Disponible en: http://www.efn.uncor.edu/departamentos/ divbioeco/divveg1/lab\%20micologia/archivos $\% 20$ fotos/afiche-hongos $\% 20$ venenosos $\% 20$ toxicos.pdf [Acceso: 14-08-2017].

DOMÍNGUEZ DÍAZ, E. 2010. Flora de interés etnobotánico usada por los pueblos originarios: Aónikenk, Selk'nam, Kawésqar, Yagan y Haush en la Patagonia Austral. Dominguezia 26: 19-29.

FERNÁNDEZ, M. V., C. BARROETAVEÑA, V. BASSANI \& F. RÍOS. 2012. Rentabilidad del aprovechamiento del hongo comestible Suillus luteus para productores forestales y para familias rurales de la zona cordillerana de la provincia del Chubut, Argentina. Bosque 33: 43-52.

FILIPOV, A. 1997. La farmacopea natural en los sistemas terapéuticos de los indígenas Pilagá. Parodiana 10: 35-74.

FLAMINI, M., G. L. ROBLEDO \& M. E. SUÁREZ. 2015. Nombres y clasificaciones de los hongos según los campesinos de La Paz (Valle de Traslasierra, Córdoba, Argentina). Bol. Soc. Argent. Bot. 50: 265-289. 


\section{Flamini et al. - Hongos útiles y tóxicos según los yuyeros de La Paz y Loma Bola}

FOSTER, G. 1994. Hippocrates' Latin American legacy: humoral medicine in the New World. Gordon and Breach Science Publishers, New York.

FURLAN, V., C. TORRES \& L. GALETTO. 2011. Conocimiento y utilización de plantas medicinales por pobladores rurales del bosque chaqueño serrano de Córdoba (Argentina). Bonplandia 20: 179-201.

GARCÍA, R. M. 2004. Guía fácil de las mejores setas. Ediciones Mundi Prensa, Madrid.

GIRI, A. \& P. RANA. 2008. Ethnomycological knowledge and nutritional analysis of some wild edible mushrooms of Sagarmatha National Park (SNP).Nepal. J. Nat. Hist. Mus. 23: 65-77.

GONZÁLEZ MONTEAGUDO, J. 2000. El paradigma interpretativo en la investigación social y educativa: nuevas respuestas para viejos interrogantes. Cuestiones pedagógicas 15: 227-246.

GUBER, R. 2001. La Etnografía: método, campo y reflexibidad. Norma, Bogotá.

GUERRERO MALDONADO, N. 2008. Uso y valoración de plantas medicinales y tintóreas presentes en Santiago del Estero, Argentina. Proyecto de fin de carrera. Universidad Politécnica de Madrid, Madrid.

HERNÁNDEZ, M. P., S. M. CIVITELLA \& V. G. ROSATO. 2010. Uso medicinal popular de plantas y líquenes de la Isla Paulino, Provincia de Buenos Aires, Argentina. BLACPMA 9: 258-268.

IDOYAGA MOLINA, A. 2001. Etiologías, síntomas y eficacia terapéutica. El proceso diagnóstico de la enfermedad en el noroeste argentino y Cuyo. Mitológicas 16: 9-43.

ILLANA ESTEBAN, C. 2012. Líquenes usados en medicina tradicional. Bol. Soc. Micol. Madrid 36: 163-174.

INDEC (Instituto Nacional de Estadísticas y Censos). 2010. República Argentina. Censo 2010.

ISE (International Society of Ethnobiology), 2006. International Society of Ethnobiology Code of Ethics (with 2008 additions). Disponible en: http:// ethnobiology.net/code-of-ethics/ [Acceso: 24-0817].

IZURIETA, G., D. ABUD \& J. IZAURRALDE. 1993. Plantaciones de pinos en la provincia de Córdoba. En: Actas de Congreso Forestal ArgentinoLatinoamericano, pp. 354-364. A.Fo.A, Paraná.

KALAC, P. 2009. Chemical composition and nutritional value of European species of wild growing mushrooms: A review. Food Chem. 113: 9-16.

KELLER, H. A. 2008. Relación entre las dimensiones del cuerpo fructífero y el pseudoesclerocio de Lentinus velutinus (Lentinaceae-Poriales), validación de una hipótesis sugerida por los guaraníes de Misiones, Argentina. Bonplandia 17: 29-34.

KELLER, H. A. 2010. Plantas colorantes utilizadas por los guaraníes de Misiones, Argentina. Bonplandia 19: 11-25.
LADIO, A. H. \& M. LOZADA. 2000. Edible wild plant use in a Mapuche community of northwestern Patagonia. Hum. Ecol. 28: 53-71.

LAGROTTERIA, M. \& M. AFFOLTER. 1999. Sustainable production and harvest of medicinal and aromatic herbs in the Sierras de Córdoba Region. Argentina. En: NAZAREA, V. D. (ed.), Ethnoecology: Situated Knowledge/Located lives, pp. 175-189. The University of Arizona Press, Tucson.

LUTI, R., M. A. BERTRAND DE SOLIS, F. M. GALERA, N. MÜlLER, M. BERZAL, M. NORES, M. A. HERRERA \& J. C. BARRERA. 1979. Vegetación. En: VÁZQUEZ, J. B., R. MIATELLO \& M. E. ROQUÉ (eds.), Geografía Física de la Provincia de Córdoba, pp. 297-368. Boldt, Córdoba.

MAHARJAN, B. L. \& B. BARAL. 2013. Antioxidant Capacity and Phenolic Content of Some Nepalese Medicinal Plants. Amer. J. Pl. Sci. 4: 1660-1665.

MALAISSE, F. 2010. How to live and survive in Zambezian open forest (Miombo ecoregion). Presses agronomiques de Gembloux, Gembloux.

MAPES, C., G. GUZMÁN \& J. CABALLERO. 1981. Etnomicología purépecha. El conocimiento y uso de los hongos en la cuenca del lago de Pátzcuaro, Michoacán. Dirección General de Culturas Populares, Secretaría de Educación Pública/Instituto de Biología, UNAM/Sociedad Mexicana de Micología, México D.F.

MARTIN, G. J. 1995. Ethnobotany: a methods manual. Chapman \& Hall, London.

MARTÍNEZ, G. J. 2007. La farmacopea natural en la salud materno-infantil de los Tobas del Río Bermejito. Kurtziana 33: 39-63.

MARTÍNEZ, G. J. 2010. Las plantas en la medicina tradicional de las sierras de Córdoba. Un recorrido por la cultura campesina de Paravachasca $y$ Calamuchita. Ediciones del Copista, Córdoba.

MARTÍNEZ, G. J.\& P. CÚNEO. 2009. Las denominaciones vernáculas y el conocimiento toba del entorno vegetal. Revista de Dialectología y Tradiciones Populares 64: 149-168.

MARTÍNEZ, G. J. \& M. C. LUJÁN. 2011. Medicinal plants used for traditional veterinary in the Sierras de Córdoba (Argentina): An ethnobotanical comparison with human medicinal uses. .J. Ethnobiol. Ethnomed. 7: 23 .

MARTÍNEZ, G. J. \& A. M. PLANCHUELO. 2003. La medicina tradicional de los criollos campesinos de Paravachasca y Calamuchita, Córdoba (Argentina). Scripta Ethnologica 25: 83-116.

MELLO AMOROZO, M. C. \& R. B. VIERTLER. 2008. A abordagem qualitativa na coleta e análise de dados etnobotânicos. En: ALBUQUERQUE, U. P., R. F. P. LUCENA \& L. V. F. C. CUNHA (eds.), Métodos e técnicas na pesquisa etnobotânica, $2^{\circ}$ ed., pp. 73-91. Comunigraf Editora, Recife. 
MONTOYA, A., S. CARMONA \&A. KONG. 1998. Intoxicaciones causadas por hongos. Fundación Produce Tlaxcala-O.P.D. Salud de TlaxcalaUniversidad Autónoma de Tlaxcala, Tlaxcala.

MORENO FUENTES, A., R. GARIBAY ORIJEL, J. TOVAR VELASCO \& J. CIFUENTES. 2001. Situación actual de la Etnomicología en México y el mundo. Etnobiología 1: 75-84.

NIVEIRO, N., O. F. POPOFF \& E. O. ALBERTÓ. 2009. Hongos comestibles silvestres: especies exóticas de Suillus (Boletales, Basidiomycota) y Lactarius (Russulales, Basidiomycota) asociadas a cultivos de Pinus elliottii del Nordeste argentino. Bonplandia 18: 65-71.

OCHOA, J. J., A. H. LADIO \& M. LOZADA. 2010. Uso de recursos herbolarios entre mapuches y criollos de la comunidad campesina de Arroyo Las Minas (Río Negro, Patagonia Argentina). BLACPMA 9: 269-276.

OKIGBO, R. N. \& C. M. NWATU. 2015. Ethnostudy and Usage of Edible and Medicinal Mushrooms in Some Parts of Anambra State, Nigeria. Natural Resources 6:79-89.

PALACIO, M. O., E. CARRIZO, M. F. EPSTEIN VITTAR \& H. J. MÜLLER. 2011. El bosque como proveedor de materia prima para la elaboración de tintes naturales en Santiago del Estero, R. Argentina. Memoria V Congreso Forestal Latinoamericano. Lima, Perú. Disponible en: http://www.cnf.org.pe/ secretaria_conflat/memorias/DOCUMENTO $\% 20$ MESAS/MESA\%204/Manuel\%20\%D3scar\%20 Palacio.pdf [Acceso: 24-08-17].

ROBLEDO, G. \& C. URCELAY. 2009. Hongos de la madera en árboles nativos del centro de Argentina. Universidad Nacional de Córdoba, Córdoba.

RODRÍGUEZ, J. M. \& C. ESTRABOU. 2008. Usnea amblyoclada «Barba de piedra» (Ascomycetes liquenizados) en Argentina. Bol. Soc. Arg. Bot. 43 (3-4): 221-225.

RUÁN-SOTO, F. 2007. 50 años de etnomicología en México. Lacandonia 1: 97-108.

RUÁN-SOTO, F., J. CIFUENTES, R.MARIACA, F. LIMÓN, L. PÉREZ-RAMÍREZ\& S. SIERRA. 2009. Uso y manejo de hongos silvestres en dos comunidades de la Selva Lacandona, Chiapas, México. Rev. Mex. Mic. 29: 61-72.

SCARPA, G. F. 2012. Las plantas en la vida de los criollos del oeste formoseño. Medicina, ganadería, alimentación y viviendas tradicionales. Asociación Civil Rumbo Sur, Buenos Aires.

SCARPA, G. F. 2013. Medicina indigena Chorote. Continuidad y transformaciones históricas $y$ culturales. Editorial Académica Española, Saarbrücken.
SCARPA, G. F., \& C. N. ROSSO. 2014. La etnobotánica moqoit inédita de Raúl Martínez Crovetto I: Descripción, actualización y análisis de la nomenclatura indígena. Bol. Soc. Argent. Bot. 49: 623-647.

SHUKLA, V., G. P. JOSHI \& M. S. RAWAT. 2010. Lichens as a potential natural source of bioactive compounds: a review. Phytochem. Rev. 9: 303-314.

SUÁREZ, M. E. 2014. Etnobotánica wichi del bosque xerófito en el Chaco Semiárido salteño. Autores de Argentina, Don Torcuato.

SUÁREZ, M. E. \& P. ARENAS. 2012. Plantas y hongos tintóreos de los wichís del Gran Chaco. Bol. Soc. Argent. Bot. 47: 275-283.

THE PLANT LIST.2013. Version 1.1. http://www. theplantlist.org/ [Acceso: 24-08-17].

TRILLO, C. \& P. DEMAIO. 2007. Tintes naturales. Guía para el reconocimiento y uso de plantas tintóreas del Centro de Argentina. Editorial Sezo, Córdoba.

TRILlO, C., B. ARIAS TOLEDO, L. GALETTO \& S. COLANTONIO. 2010. Persistence of the Use of Medicinal Plants in Rural Communities of the Western Arid Chaco (Córdoba, Argentina). Open Complement. Med. J. 2: 80-89.

VAN DIJK, H., N. A. ONGUENE \& T. W. KUYPER. 2003. Knowledge and utilization of edible mushrooms by local population of the rain forest of south Cameroon. Ambio 32:19-23.

WAHYUNI, D. 2012. The Research Design Maze: Understanding Paradigms, Cases, Methods and Methodologies. JAMAR 10: 69-80.

WENDAKOON, C., P. CALDERON \& D. GAGNON. 2012. Evaluation of selected medicinal plants extracted in different ethanol concentrations for antibacterial activity against human pathogens. Journal of Medicinally Active Plants 1: 60-68.

YAMIN-PASTERNAK, S. 2011. Ethnomycology: Fungi and Mushrooms in Cultural Entanglements. En: ANDERSON, E. N., D. M. PEARSALL, E. S. HUNN \& N. J. TURNER (eds.), Ethnobiology, pp. 213-230. Wiley-Blackwell, Hoboken.

ZAK, M. R., M. CABIDO \& J. G. HODGSON. 2004. Do subtropical seasonal forests in the Gran Chaco, Argentina, have a future? Biol. Conservation 120: 589-598.

Recibido el 20 de septiembre de 2017, aceptado el 28 de diciembre de 2018. Editor: Leopoldo Iannone. 